\title{
Prevalence of enteropathogenic viruses and molecular characterization of group A rotavirus among children with diarrhea in Dar es Salaam Tanzania
}

\author{
Sabrina J Moyo*1, Njolstad Gro², Vainio Kirsti³, Mecky I Matee1, \\ Jesse Kitundu ${ }^{4}$, Samwel Y Maselle ${ }^{1}$, Nina Langeland ${ }^{5,6}$ and Helge Myrmel ${ }^{2}$
}

\begin{abstract}
Address: ${ }^{1}$ Department of Microbiology and Immunology, School of Medicine, Muhimbili University of Health and Allied Sciences, Dar es Salaam, Tanzania, ${ }^{2}$ Department of Microbiology and Immunology, Haukeland University Hospital, Bergen, Norway, ${ }^{3}$ Department of Virology, Norwegian Institute of Public Health, Oslo, Norway, ${ }^{4}$ Department of Paediatrics and Child Health, Muhimbili National Hospital, Dar es Salaam, Tanzania, ${ }^{5}$ Institute of Medicine, University of Bergen, Bergen, Norway and ${ }^{6}$ Department of Medicine, Haukeland University Hospital, Bergen, Norway

Email: Sabrina J Moyo* - sabmoyo26@yahoo.com; Njolstad Gro - gro.njolstad@helse-bergen.no; Vainio Kirsti - Kirsti.Vainio@fhi.no; Mecky I Matee - mateerrr@yahoo.com; Jesse Kitundu - jkitundu@muchs.ac.tz; Samwel Y Maselle - smaselle@muchs.ac.tz; Nina Langeland - nina.langeland@helse-bergen.no; Helge Myrmel - helge.myrmel@haukeland.no

* Corresponding author
\end{abstract}

Published: 27 December 2007

BMC Public Health 2007, 7:359 doi:10.1 186/1471-2458-7-359
Received: 7 July 2007

Accepted: 27 December 2007

This article is available from: http://www.biomedcentral.com/147I-2458/7/359

(c) 2007 Moyo et al; licensee BioMed Central Ltd.

This is an Open Access article distributed under the terms of the Creative Commons Attribution License (http://creativecommons.org/licenses/by/2.0), which permits unrestricted use, distribution, and reproduction in any medium, provided the original work is properly cited.

\begin{abstract}
Background: Different groups of viruses have been shown to be responsible for acute diarrhea among children during their first few years of life. Epidemiological knowledge of viral agents is critical for the development of effective preventive measures, including vaccines.

Methods: In this study we determined the prevalence of the four major enteropathogenic viruses - rotavirus, norovirus, adenovirus and astrovirus - was determined in 270 stool samples collected from children aged 0-60 months who were admitted with diarrhea in four hospitals in Dar es Salaam, Tanzania, using commercially available ELISA kits. In addition, the molecular epidemiology of group A rotavirus was investigated using reverse transcriptase multiplex polymerase chain reaction (RT-PCR).
\end{abstract}

Results: At least one viral agent was detected in $87 / 270$ (32.2\%) of the children. The prevalence of rotavirus, norovirus, adenovirus and astrovirus was $18.1 \%, 13.7 \%, 2.6 \%$ and $0.4 \%$, respectively. In most cases $(62.1 \%$ ) of viruses were detected in children aged 7-12 months. The $G$ and $P$ types (VP7 and VP4 genotypes respectively) were further investigated in 49 rotavirus ELISA positive samples. $\mathrm{G} 9$ was the predominant $\mathrm{G}$ type $(81.6 \%)$, followed by $\mathrm{GI}(10.2 \%)$ and $\mathrm{G} 3(0.2 \%)$. P $[8]$ was the predominant $P$ type (83.7\%), followed by $P[6](0.4 \%)$ and $P[4](0.2 \%)$. The following $G$ and $P$ types were not detected in this study population; G2, G4, G8 GI0, P[9], P[I0] and P[II]. The dominating G/P combination was G9P[8], accounting for 39 (90.7\%) of the 43 fully characterized strains. Three (6.1\%) of the 49 rotavirus strains could not be typed.

Conclusion: Nearly one third of children with diarrhea admitted to hospitals in Dar es Salaam had one of the four viral agents. The predominance of rotavirus serotype G9 may have implication for rotavirus vaccination in Tanzania. 


\section{Background}

In Dar es Salaam Tanzania relatively few studies have investigated viral causes of diarrhea. These studies, which were conducted more than ten years ago, searched for a relatively narrow spectrum of viruses $[1,2]$. There has been only one recent study conducted in Ifakara, Tanzania which is about 500 KM away from Dar es Salaam which reported prevalence of rotavirus [3]. These studies used either latex agglutination test methods or electron microscopy, techniques which have been reported to be less sensitive and less specific than EIA [4,5]. Despite the reported predominance of rotavirus the molecular epidemiology of group A rotavirus strains in Tanzania is not known resulting in lack of important information for the introduction of a suitable rotavirus vaccine in future.

Several different groups of viruses have been shown to be responsible for the high incidence of acute viral diarrhea among children during their first few years of life [6]. These viruses include rotavirus [7], noroviruses [4], enteric adenovirus 40/41 [4] and astrovirus [8]. Among them, rotavirus is the single most important etiological agent in severe dehydrating diarrhea, causing approximately 111 million episodes of gastroenteritis, 25 million clinic visits, 2 million hospitalizations and 440,000 deaths in children aged less than five years of age each year worldwide [9]. Most human rotaviruses belong to group A [4]. The outer capsid layer of the virus consist of two proteins carrying distinct epitopes (VP7 and VP4), which are specifically determined by neutralizing antibody responses, and thus characterize serotype of rotaviruses [10]. The VP7-specific serotypes are termed G types (G stands for glycoprotein) and VP4-specific serotypes are termed $\mathrm{P}$ types ( $\mathrm{P}$ stands for protease-sensitive protein). The genes coding for VP4 and VP7 proteins have been used for genotypic classification of strains. Among group A rotaviruses, 15 different $G$ serotypes and 26 different $P$ types have beeen identified to date and there is coexistance of different $\mathrm{G}$ and $\mathrm{P}$ combinations among rotaviruses. Initially almost all episodes were found to be caused by G1-G4 types, but gradually the occurrence of G12, G9, G5, G8 and G10 genotypes has been reported from several countries [11]. G/P combinations due to $G$ type of VP7 gene and P VP4 gene are useful characteristics to distinguish rotaviruses. There are significant geographical differences regarding the strain distributions [12]. Studies of rotavirus strain diversity have traditionally employed VP7-specific neutralizing monoclonal antibodies in enzyme immunoassays (EIAs) to detect the common VP7 serotype in stool. However, a substantial number of strains remain nontypeable by EIA [13]. Furthermore, serologic methods to detect common VP4 serotypes are not routinely available. Currently molecular methods such as RT-PCR and probe hybridization have been developed for both VP7 and VP4 typing $[13,14]$.
Our study aimed to determine the prevalence of four important diarrheagenic virues viz. rotavirus, norovirus, enteric adenovirus and astrovirus among children less than five years of age who had to be hospitalized due to diarrhea in Dar es Salaam, Tanzania. In addition molecular typing of Group A rotavirus strains was also performed using RT-PCR.

\section{Methods \\ Study design and subjects}

This was a prospective cross-sectional study that was conducted in Dar es Salaam city which has three districts with 4 large public hospitals and 4 big private hospitals. The four public hospitals are the largest hospitals in Dar es Salaam. Three of these (Amana, Mwananyamala, and Temeke district hospital) which are located at each district of Dar es Salaam are secondary health care facilities while one (Muhimbili National Hospital, MNH) is a tertiary health care facility. This study was conducted at MNH, Amana, Mwananyamala, and Temeke district Hospitals between December 2005 and February 2006. These hospitals handle patients with severe disease and those that need admission. Being public facilities they cover approximately $70 \%$ of the patient load and the remaining $30 \%$ is handled by the private hospitals especially for patients who are able to pay. The catchments area of these hospitals is Dar es Salaam city which has a population of around 4 million.

During the study period a total of 297 children who were hospitalized owing to diarrhea were enrolled in this study. Enrolment was subject to obtaining an informed verbal consent from the parent or guardian who accompanied the child. Children whose parents/guardians did not consent and those whose age could not be ascertained were excluded from the study. Seventeen of these children were excluded from the study due to lack of consent or uncertainty of age while 10 were excluded due to improperly collected specimen.

\section{Demographic and clinical information}

A standard structured questionnaire was used to obtain the information regarding the age, sex, duration, frequency of diarrhea and consistency of the stool (as watery, mucoid, or bloody) for each case. Diarrhea was defined, according to WHO guidelines [15], as the occurrence of three or more, loose, liquid, or watery stools within 24 hour period. The guidelines define three forms of diarrhea viz. i) acute watery diarrhea for diarrhea that began acutely and lasted less than 14 days, ii) dysentery defined as mucoid bloody stool associated with anorexia, abdominal cramps, and tenesmus and iii) persistent diarrhea defined as diarrhea with a duration of 14 or more days without remission in between. Information regarding the use of antibiotics prior to hospitalization was also sought. 


\section{Weight measurements}

Infants under two years of age were weighed using a $25 \mathrm{~kg}$ Salter hanging scales (CMS Weighing equipment, High Holborn, London, United Kingdom). Children over two years of age were weighed while standing on scales that were calibrated before each session. Weight of children was recorded to the nearest kilogram. Weight-for age Z-scores were calculated using EPI Info (USD, Inc., Stone Mountain, GA). According to WHO criteria [16] children were considered to be undernourished if the Z-scores were less than -2SD.

\section{Specimen collection and transportation}

Stool specimens were collected using wide mouthed sterile plastic containers and a portion of specimen was stored in $1.8 \mathrm{~m}$ plastic nunc tubes (Nalge Nunc International, NY, USA) at $-20^{\circ} \mathrm{C}$ until the time for analysis. All the specimens were subjected to one cycle of thawing and freezing.

\section{Laboratory procedures}

Detection of rotavirus, norovirus, adenovirus and astrovirus

The presence of four enteric viruses namely Rotavirus, norovirus, adenovirus and astrovirus antigens was investigated using the suspension of stool samples by commercial immunoassays IDEIA Rotavirus, IDEIA Adenovirus, and IDEIA Astrovirus and IDEIA Norovirus (Dako Ltd., Ely, United Kingdom) according to the manufacturer's instructions.

\section{Molecular typing of rotavirus}

\section{RNA extraction and Reverse Transcription (RT)}

Rotavirus antigen-positive stool samples were mixed 1:10 with Eagles Minimum Essential Medium, and clarified by low-speed centrifugation. Double-stranded RNA was extracted from $140 \mu$ l supernatant using the Magna Pure LC Total Nucleic Acid Isolation Kit (Roche Applied Science). RNA was additionally extracted from a subset of samples using the QIAamp Viral RNA Mini Kit (Qiagen/Westburg, Leusden, and the Netherlands). Both kits were used according to the manufacturer's instructions. $40 \mu \mathrm{l}$ of RNA extract was used as template for RT with random primers.

\section{Rotavirus genotyping using multiplex PCR}

Rotavirus $G$ an $P$ genotyping was performed using seminested type specific multiplex PCR's that could detect seven G-types (G1, G2, G3, G4, G8, G9, G10) and six P-types $\mathrm{P}[4], \mathrm{P}[6], \mathrm{P}[8], \mathrm{P}[9], \mathrm{P}[10]$ and $\mathrm{P}[11]$, respectively [17]. The P-typing was performed using modified first round primers according to rotavirus detection and typing protocol provided by Dr J. Gray, HPA, UK. Briefly, the first round VP4 and VP7 consensus PCR's were carried out with $5 \mu \mathrm{l}$ of cDNA in $50 \mu \mathrm{l}$ of each of the VP4 and VP7 reagent mixtures, respectively. The second round VP4 and VP7 multiplex PCR's were carried out with 2 ul of first round VP4 and VP7 amplicons in $50 \mu \mathrm{l}$ of each of the second round VP4 and VP7 reagent mixtures, respectively. The multiplex PCR mix- tures contained $10 x$ buffer II without $\mathrm{MgCl}_{2}$ (Invitrogen), $\mathrm{MgCl}_{2}$ (2 mM and $2.5 \mathrm{mM}$ respectivel $\gamma$ ), deoxynucleoside triphosphates $(0.2 \mathrm{mM})$, primers $(20 \mathrm{pmol})$, and Taq DNA polymerase (1U) (Invitrogen). PCR was performed at $94^{\circ} \mathrm{C}$ for $2 \mathrm{~min}$, followed by 35 cycles at $94^{\circ} \mathrm{C}$ for $1 \mathrm{~min}, 50^{\circ} \mathrm{C}$ and $52^{\circ} \mathrm{C}$ for $1 \mathrm{~min}$, and $72^{\circ} \mathrm{C}$ for $1 \mathrm{~min}$ and a final extension at $72^{\circ} \mathrm{C}$ for $7 \mathrm{~min}$, and then the mixture was held at $15^{\circ} \mathrm{C}$. PCR products were subjected to electrophoresis on a $2 \%$ agarose gel, stained with ethidium bromide, and observed under ultraviolet light. The different $G$ and $P$ types were analyzed by comparing the size of the second round PCR-products with PCR-products of known rotavirus strains. The untypeable rotavirus strains were further analyzed using a single-round rotavirus VP6 specific PCR following rotavirus detection and typing protocol provided by Dr J. Gray, HPA, UK. Negative and positive controls were used in all PCR assays.

\section{Data management}

The Statistical Package for the Social Sciences (SPSS for WINDOWS version 10.0) was used for statistical analysis. Weight-for age $\mathrm{z}$ scores were calculated using EPI Info (USD, Inc., Stone Mountain, GA). Assuming the data follows a normal distribution, comparison of proportions and statistical significance were tested by using the Chi-square test. A p value less than 0.05 was considered statistically significant

\section{Ethical considerations}

Ethical and research clearance was obtained from the Higher Degree Research and Publication Committee, Muhimbili University College of Health Sciences, Dar es Salaam. Permission was sought from the respective hospital authorities. Informed verbal consent was obtained from parents/caretaker of the child before enrolment into the study. Children were treated according to IMCI guidelines [15].

\section{Results \\ Prevalence of rotavirus, norovirus, adenovirus and astrovirus}

Among the 270 stool specimens collected from children with diarrhea, 87 (32.2\%) contained at least one of the four viruses. Table 1 shows the frequency of each individual viral agent as follows: rotavirus 49 (18.1\%), norovirus $37(13.7 \%)$, enteric adenovirus $7(2.6 \%)$ and astrovirus 1 $(0.4 \%)$. Using commercial EIA's kit, multiple viral infections were found in seven out of the 87 positive samples $(8.0 \%)$. Six were co-infections of rotavirus and norovirus and one sample contained rotavirus and adenovirus.

\section{Association between age group and viral enteric pathogens isolated}

As shown in Table 2, only one virus (norovirus) was detected in the age group of 0-2 months, the prevalence 
of viruses was low in infants aged 0-6 months, peaked in infants aged 7-12 months and declined again among children of 13-16 months of age ( $p>0.05)$.

\section{Rotavirus genotyping}

Rotavirus was detected in 49 out of 270 (18.1\%) samples tested. Of the 49 rotavirus ELISA positive samples, 43 (87.7\%) were fully G and P genotyped by RT-PCR, 3 $(6.0 \%)$ were partially genotyped, while $3(6.0 \%)$ could not be genotyped. In total 46 samples were $\mathrm{G}$ typeable, and the dominant $\mathrm{G}$ type was G9 40 (81.6\%), followed by G1 (10.2\%), and G3 (2.0\%) (Table 3). The genotypes G2, G4, G8 and G10 were not detected in this study. As shown in Table 4, 44 samples were $P$ typeable. $P[8]$ predominated accounting for 41 (83.7\%) of the $44 \mathrm{P}$ typeable strains. Only two P[6] strains and one P[4] strain was detected, whereas $P[9], P[10]$ and $P[11]$ strains were not detected. The most prevalent $\mathrm{P} / \mathrm{G}$ combination was G9P[8], accounting for 39/43 (90.7\%) of the fully characterized strains. The two $\mathrm{P}[6]$ isolates were $\mathrm{G} 1 \mathrm{P}[6]$, where as one $\mathrm{P}[4]$ was untypeable.

\section{Discussion}

The present study was conducted during the dry season of the year and showed that nearly one-third (31.9\%) of diarrhea among under fives in Dar es Salaam is due to the four major viruses causing diarrhea in children, namely rotavirus, norovirus, adenovirus and astrovirus. Of the four viruses, rotavirus was by far the most frequently isolated, accounting for $57.5 \%$ of all the viruses and followed

Table I: Prevalence of four enteric viruses among underfives with diarrhea in Dar es Salaam Tanzania.

\begin{tabular}{lcc}
\hline Enteric virus & $\mathrm{n}=270$ & $\%$ \\
\hline $\begin{array}{l}\text { No of children with } \\
\text { at least one virus }\end{array}$ & 87 & 32.2 \\
Rotavirus & 49 & 18.1 \\
Norovirus & 37 & 13.7 \\
Adenovirus & 7 & 2.6 \\
Astrovirus & 1 & 0.4 \\
Dual infection & 7 & 2.6
\end{tabular}

by norovirus that accounted for $42.5 \%$ of the viruses. Overall rotavirus accounted for $18.5 \%$ of all cases of diarrhea which is lower than other findings in Tanzania which reported rotavirus to account for up to $43 \%$ of diarrhea cases [2,3]. The difference between these two studies could be explained, at least in part, due to seasonal differences and by the use in the previous studies of the less specific agglutination tests which may lead to false positive results compared to ELISA [18].

The frequency of detection of norovirus found in this study $(13.7 \%)$ is in keeping with numerous other studies conducted in both developing and developed countries that have reported norovirus to be responsible for between 10 and 15\% of all cases of gastroenteritis [4]. This is one of the very few reports on norovirus gastroenteritis in developing countries [19-22], therefore further studies are needed to ascertain the disease burden associated with this virus in developing countries.

We found a relatively low rate of enteric adenovirus $(2.6 \%)$ which is in agreement with a previous report of $2.7 \%$ in Dar es Salaam[1] suggesting that adenoviruses play relatively little role in causing diarrhea among children in Tanzania.

We detected only one astrovirus (0.4\%) in this study group. This is the first report to examine the epidemiology of astrovirus in patients with gastroenteritis in Tanzania, and our finding suggests that the virus account for only a minority of diarrhea cases.

Using commercial EIA kit, we found dual viral infections among seven $(8.0 \%)$ samples, all of which were combinations of rotavirus and one of the other viruses. E. Roman et al 2003 [23], reported high incidence of dual infections during autumn than other seasons of the year this can not be concluded in this study since it was conducted in only one season of the year. Despite using standard multiplex PCR typing, no mixed rotavirus infections were detected in this study. In other studies, mixed rotavirus infections have been identified to range from less than 1\% to $44.6 \%$ of the samples [24-30]. Differences found between this

Table 2: Association between age group and viral enteric pathogens isolated among under fives with diarrhea in Dar es Salaam

\begin{tabular}{|c|c|c|c|c|c|}
\hline & Total & Rotavirus & Norovirus & Adenovirus & Astrovirus \\
\hline \multicolumn{6}{|c|}{ Age group in months } \\
\hline $0-2$ & 4 & 0 & I (2.8) & 0 & 0 \\
\hline $3-6$ & 46 & $13(26.0)$ & $8(22.2)$ & 0 & 0 \\
\hline $7-12$ & 133 & 25 (52.0.) & $20(54.2)$ & $6(85.7)$ & $I(100)$ \\
\hline $13-24$ & 63 & $9(18.0)$ & 7 (19.4) & $\mathrm{I}(14.3)$ & 0 \\
\hline $25-60$ & 24 & $2(4.0)$ & $\mathrm{I}(2.8)$ & 0 & 0 \\
\hline Total & 270 & 49 & 37 & 7 & I \\
\hline
\end{tabular}


Table 3: Prevalence of $\mathbf{G}$ genotype of Group A rotavirus detected among underfive children with diarrhea in Dar es Salaam Tanzania

\begin{tabular}{ll}
\hline G genotype & $\mathrm{n}=49$ \\
\hline $\mathrm{G} 9$ & $40(81.6 \%)$ \\
$\mathrm{GI}$ & $5(10.2 \%)$ \\
G3 & $\mathrm{I}(2.0 \%)$ \\
G2,G4,G8 and G10 & $0(0.0 \%)$ \\
G untypable & $3(6.1 \%)$ \\
\hline
\end{tabular}

Table 4: Prevalence of $P$ genotype of Group A rotavirus detected among underfive children with diarrhea in Dar es Salaam Tanzania

\begin{tabular}{lc}
\hline$P$ genotype & $\mathrm{n}=49$ \\
\hline $\mathrm{P}[8]$ & $4 \mathrm{I}(83.7 \%)$ \\
$\mathrm{P}[6]$ & $2(4.1 \%)$ \\
$\mathrm{P}[4]$ & $\mathrm{I}(2.0 \%)$ \\
$\mathrm{P}[6], \mathrm{P}[9], \mathrm{P}[\mathrm{I0}]$ and $\mathrm{P}[\mathrm{II}]$ & $0(0.0 \%)$ \\
$\mathrm{P}$ untypable & $5(10.2)$ \\
\hline
\end{tabular}

study and other studies may be explained, at least in part, due to geographical differences.

Overall the prevalence of viral diarrhea was low in infants aged 0-6 months, peaked in infants aged 7-12 months and declined again among children of 13-16 months of age. The relatively low prevalence of viruses among older children could be partly due to immunity acquired through previous exposures.

This first report on molecular epidemiology of rotavirus strains in Tanzania show unexpectedly high proportion of G9 serotype (81.6\%). The high proportion of G9 in this study is in contrast with findings of other developing countries such as Kenya, Malawi and Ghana, where the highest reported prevalence of G9 was $47.1 \%$ [31-38]. The complete absence of serotypes G2 and G4 in this study group is in marked contrast to the global situation, where these strains are often the most common [12]. This variation of strain distribution does underline the importance of active rotavirus strain surveillance in a variety of geographical settings. Our findings may have significant implications for rotavirus vaccine introduction in Tanzania since the two vaccines that are in use namely RotaRix ${ }^{\circledast}$ and RotaTeq ${ }^{\varpi}$ contains serotype G1 and serotype G1 to G4, respectively [10]. Notably, the globally most prevalent $\mathrm{P}[8]$ genotype was detected for VP4 in $93.7 \%$ of the P-typed strains and the dominating G/P combination was G9 P[8] (90.7\%). It is important to mention that this study dealt with strains isolated from only one city in Tanzania (in and around Dar es Salaam) and the period of surveillance was limited to a period of 3-months. It will be important to continue strain characterization in Dar es Salaam and initiate studies in other regions of Tanzania in order to have a comprehensive picture of strain distribution in the country. It is equally important to maintain continuous surveillance for rotavirus strains in order to monitor changes over a time period.

\section{Conclusion}

This study demonstrated that about one third of childhood diarrhea in Dar es Salaam is due to one of the four major enteropathogenic viruses and rotavirus genotype G9 predominated. The predominance of this emerging strain has significant implications for introduction of rotavirus vaccine in Tanzania. Our study indicates that geographical P-G type adjustment in the formulation of next generation multivalent vaccine would be necessary.

\section{Competing interests}

The author(s) declare that they have no competing interests.

\section{Authors' contributions}

SJM was the principal investigator, who conceived and designed study and was responsible for collection of specimens and clinical information as well as data analysis. Laboratory investigations were performed by SJM, NG and KV. SYM, MIM, JK, NL and HM assisted in the development of the research proposal, data analysis and preparation of the manuscript. All authors have read and approved the final manuscript.

\section{Acknowledgements}

We would like to thank the administration of the Muhimbili National Hospital, Ilala, Mwananyamala and Temeke Municipal Hospitals for giving necessary administrative support. We would also like to thank the parents/ guardians of the children who participated in this study, without whom this study would have not been possible. We acknowledge the technical support accorded to this study by members of the Departments of Microbiology and Immunology of the Muhimbili University College of Health Sciences (MUCHS) in Dar es Salaam, Tanzania, Haukeland University Hospital in Bergen, Norway and the Norwegian Public Health Institute in Oslo, Norway. The financial support by the Western Norway Regional Health Authority and the Gade Legacy Institute is acknowledged.

\section{References}

I. Mhalu FS, Myrmel H, Msengi A, Haukenes G: Prevalence of infection with rotavirus and enteric adenoviruses among children in Tanzania. NIPH Ann 1988, I I(I):3-7.

2. Sam NE, Haukenes G, Szilvay AM, Mhalu F: Rotavirus infection in Tanzania: a virological, epidemiological and clinical study among young children. Apmis 1992, I00(9):790-796.

3. Vargas M, Gascon J, Casals C, Schellenberg D, Urassa H, Kahigwa E, Ruiz J, Vila J: Etiology of diarrhea in children less than five years of age in Ifakara, Tanzania. Am J Trop Med Hyg 2004, 70(5):536-539.

4. Wilhelmi I, Roman E, Sanchez-Fauquier A: Viruses causing gastroenteritis. Clin Microbiol Infect 2003, 9(4):247-262.

5. Wilhelmi I, Colomina J, Martin-Rodrigo D, Roman E, Sanchez-Fauquier A: New immunochromatographic method for rapid detection of rotaviruses in stool samples compared with 
standard enzyme immunoassay and latex agglutination techniques. Eur J Clin Microbiol Infect Dis 200I, 20(10):74I-743.

6. Giordano MO, Ferreyra LJ, Isa MB, Martinez LC, Yudowsky SI, Nates SV: The epidemiology of acute viral gastroenteritis in hospitalized children in Cordoba City, Argentina: an insight of disease burden. Rev Inst Med Trop Sao Paulo 200I, 43(4): I93-I 97.

7. Castello AA, Arguelles MH, Rota RP, Olthoff A, Jiang B, Glass RI, Gentsch JR, Glikmann G: Molecular epidemiology of group A rotavirus diarrhea among children in Buenos Aires, Argentina, from 1999 to 2003 and emergence of the infrequent genotype G I 2. J Clin Microbiol 2006, 44(6):2046-2050.

8. Walter JE, Mitchell DK: Role of astroviruses in childhood diarrhea. Curr Opin Pediatr 2000, I 2(3):275-279.

9. Parashar UD, Hummelman EG, Bresee JS, Miller MA, Glass RI: Global illness and deaths caused by rotavirus disease in children. Emerg Infect Dis 2003, 9(5):565-572.

10. Parashar UD: Prevention of rotavirus gastroenteritis among infants and children: Recommendations of the Advisory Committee on Immunization Practices (ACIP). MMWR Recomm Rep 2006, 55(RR-I-I 2): I- I3.

II. Okitsu-Negishi S, Nguyen TA, Phan TG, Ushijima H: Molecular epidemiology of viral gastroenteritis in Asia. Pediatr Int 2004 46(2):245-252.

12. Santos N, Hoshino Y: Global distribution of rotavirus serotypes/genotypes and its implication for the development and implementation of an effective rotavirus vaccine. Rev Med Virol 2005, I5(I):29-56.

13. Gouvea V, Glass RI, Woods P, Taniguchi K, Clark HF, Forrester B, Fang ZY: Polymerase chain reaction amplification and typing of rotavirus nucleic acid from stool specimens. J Clin Microbiol 1990, 28(2):276-282.

14. Gentsch JR, Glass RI, Woods P, Gouvea V, Gorziglia M, Flores J, Das $B K$, Bhan MK: Identification of group A rotavirus gene 4 types by polymerase chain reaction. J Clin Microbiol 1992, 30(6): 1365-1373.

15. IMCl Integrated Mangagement of Childhood Illness. Model Chapter for Textbooks. Document no WHO/FCH/CAH/00.40 Geneva: World Health Organization; 200I.

16. Waterlow JC, Buzina R, Keller W, Lane JM, Nichaman MZ, Tanner JM: The presentation and use of height and weight data for comparing the nutritional status of groups of children under the age of I 0 years. Bull World Health Organ 1977, 55(4):489-498.

17. Iturriza-Gomara M, Kang G, Gray J: Rotavirus genotyping: keeping up with an evolving population of human rotaviruses. Clin Virol 2004, 3 I (4):259-265.

18. Flewett TH, Arias CF, Avendano LF, Ghafoor A, Mathan MM, Mendis L, Moe K, Bishop RF: Comparative evaluation of the WHO and DAKOPATTS enzyme-linked immunoassay kits for rotavirus detection. Bull World Health Organ 1989, 67(4):369-374.

19. Armah GE, Gallimore $\mathrm{Cl}$, Binka FN, Asmah RH, Green J, Ugoji U, Anto F, Brown DW, Gray J): Characterisation of norovirus strains in rural Ghanaian children with acute diarrhoea. J Med Virol 2006, 78(I I): | 480-5.

20. Nakata Shuji, Honma Shinjiro, Numata Kazuko, Kogawa Keiko, Ukae Susumu, Adachi Noriaki, Jiang Xi, Estes Mary K, Gatheru Zippora, Tukei Peter M, Chiba Shunzo: Prevalence of Human Calicivirus Infections in Kenya as Determined by Enzyme Immunoassays for Three Genogroups of the Virus. J Clin Microbiol 1998, 36(II):3160-3163.

21. Smit TK, Bos P, Peenze I, Jiang X, Estes MK, Steele AD: Seroepidemiological study of genogroup $I$ and II calicivirus infections in South and southern Africa. J Med Virol 1999, 59(2):227-3I.

22. Monica B, Ramani S, Banerjee I, Primrose B, Iturriza-Gomara M, Gallimore Cl, Brown DWMF, Moses PD, Gray J], Kang G: Human caliciviruses in symptomatic and asymptomatic infections in children in Vellore, South India. J Med Virol 2007, 79(5):544-5 I.

23. Roman Enriqueta, Wilhelmi Isabelll, Colomina Javier, Villar Joaquin, Cilleruelo Maria Luz, Nebreda Veronica, Del Alamo Manuel, SanchezFauquier : Acute viral gastroenteritis: proportion and clinical relevance of multiple infections in Spanish children. J Med Microbiol 2003, 52:435-440.

24. Carvalho-Costa FA, Assis RM, Fialho AM, Boia MN, Alves DP, Martins CM, Leite JP: Detection and molecular characterization of group A rotavirus from hospitalized children in Rio de Janeiro, Brazil 2004. Mem Inst Oswaldo Cruz 2006, I0 I(3):291-4.
25. Fischer TK, Eugen-Olsen J, Pedersen AG, Molbak K, Bottiger B, Rostgaard K, Nielsen NM: Characterization of rotavirus strains in a Danish population: high frequency of mixed infections and diversity within the VP4 gene of P[8] strains. J Clin Microbiol 2005, 43(3): 1099-104.

26. Fischer TK, Page NA, Griffin DD, Eugen-Olsen J, Pedersen AG, Valentiner-Branth P, Mølbak K, Sommerfelt H, Nielsen NM: Characterization of incompletely typed rotavirus strains from GuineaBissau: identification of G8 and G9 types and a high frequency of mixed infections. Virol 2003, 3 I I ( I): I 25-I33.

27. Barril PA, Martinez LC, Giordano MO, Castello AA, Rota RP, Isa MB, Masachessi G, Ferreyra LI, Glikmann G, Nates SV: Detection of group A human rotavirus G9 genotype circulating in Cordoba, Argentina, as early as 1980. J Med Virol 2006, 78(8): | | | 3-8

28. Arguelles $\mathrm{MH}$, Villegas GA, Castello A, Abrami A, Ghiringhelli PD, Semorile L, Glikmann G: VP7 and VP4 genotyping of human group A rotavirus in Buenos Aires, Argentina. J Clin Microbiol 2000, 38(I):252-9.

29. Nielsen NM, Eugen-Olsen J, Aaby P, Molbak K, Rodrigues A, Fischer TK: Characterisation of rotavirus strains among hospitalised and non-hospitalised children in Guinea-Bissau, 2002 A high frequency of mixed infections with serotype G8. J Clin Virol 2005, 34(I):|3-2|

30. Sanchez-Fauquier A, Montero V, Moreno S, Sole M, Colomina J, Iturriza-Gomara M, Revilla A, Wilhelmi I, Gray J, Gegavi/VIGESS-Net Group: Human rotavirus $\mathbf{G 9}$ and $\mathbf{G} 3$ as major cause of diarrhea in hospitalized children, Spain. Emerg Infect Dis 2006, I 2(10):|536-4|.

3I. Nakata S, Gatheru Z, Ukae S, Adachi N, Kobayashi N, Honma S, Muli J, Ogaja P, Nyangao J, Kiplagat E, Tukei PM, Chiba S: Epidemiological study of the $\mathbf{G}$ serotype distribution of group A rotaviruses in Kenya from 1991 to 1994. J Med Virol 1999, 58(3):296-303.

32. Cunliffe NA, Gondwe JS, Broadhead RL, Molyneux ME, Woods PA, Bresee JS, Glass RI, Gentsch JR, Hart CA: Rotavirus $\mathbf{G}$ and $\mathbf{P}$ types in children with acute diarrhea in Blantyre, Malawi, from 1997 to 1998: predominance of novel P[6] G8 strains. J Med Virol 1999, 57(3):308-312.

33. Cunliffe NA, Gondwe JS, Graham SM, Thindwa BD, Dove W, Broadhead RL, Molyneux ME, Hart CA: Rotavirus strain diversity in Blantyre, Malawi, from 1997 to 1999. I Clin Microbiol 200I, 39(3):836-843.

34. Arguelles $M H$, Villegas GA, Castello A, Abrami A, Ghiringhelli PD, Semorile L, Glikmann G: VP7 and VP4 genotyping of human group A rotavirus in Buenos Aires, Argentina. J Clin Microbiol 2000, 38(I):252-259.

35. Armah GE, Steele AD, Binka FN, Esona MD, Asmah RH, Anto F, Brown D, Green J, Cutts F, Hall A: Changing patterns of rotavirus genotypes in ghana: emergence of human rotavirus $G 9$ as a major cause of diarrhea in children. J Clin Microbiol 2003 , 4I(6):23I $7-2322$

36. Asmah RH, Green J, Armah GE, Gallimore $\mathrm{Cl}$, Gray IJ, IturrizaGómara M, Anto F, Oduro A, Binka FN, Brown DW, Cutts F: Rotavirus $\mathbf{G}$ and $\mathbf{P}$ genotypes in rural Ghana. J Clin Microbiol 200I, 39(5): $1981-1984$

37. Cunliffe NA, Dove W, Bunn JE, Ben Ramadam M, Nyangao JW, Riveron RL, Cuevas LE, Hart CA: Expanding global distribution of rotavirus serotype G9: detection in Libya, Kenya, and Cuba. Emerg Infect Dis 200 I, 7(5):890-2.

38. Kiulia NM, Peenze I, Dewar J, Nyachieo A, Galo M, Omolo E, Steele $A D$, Mwenda JM: Molecular characterisation of the rotavirus strains prevalent in Maua, Meru North, Kenya. East Afr Med J 2006, 83(7):360-5

\section{Pre-publication history}

The pre-publication history for this paper can be accessed here:

http://www.biomedcentral.com/1471-2458/7/359/ prepub 